\title{
Adaptive gender-based thermal control system
}

\author{
Jamal I. Al-Nabulsi' ${ }^{1}$, Bashar E. A. Badr ${ }^{2}$ \\ ${ }^{1}$ Medical Engineering Department, Al-Ahliyya Amman University, Amman, Jordan \\ ${ }^{2}$ Electrical Engineering Department, Al-Ahliyya Amman University, Amman, Jordan
}

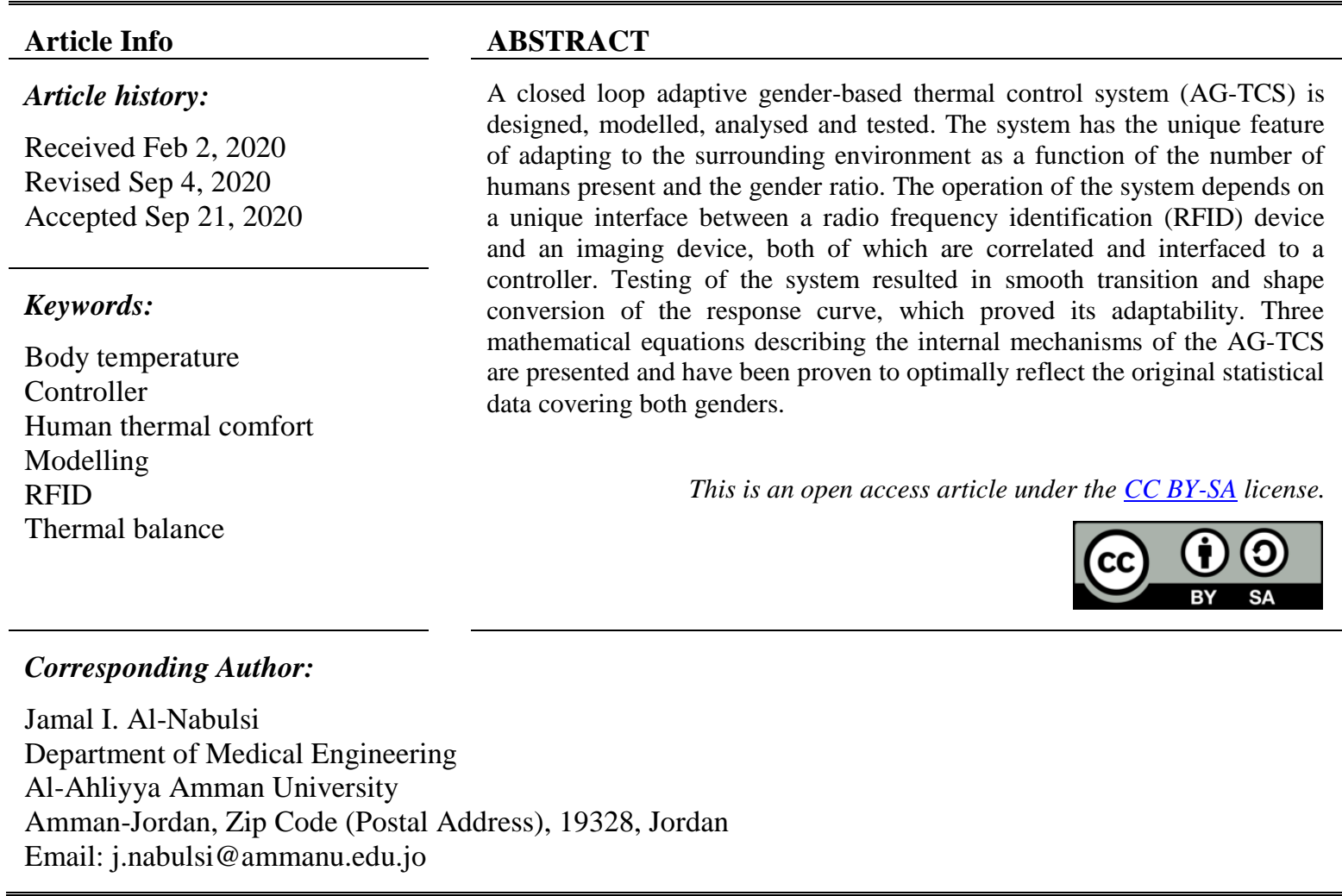

\section{INTRODUCTION}

Human thermal comfort is becoming an important research topic in the field of medical engineering whereby researchers and engineers are expected to develop and provide a comfortable indoor environment with low energy consumption characteristics. Such requirements entail the provision of adaptable air conditioning systems able to detect, classify, and predict temperature changes in an enclosed environment. The intelligent system proposed should be able to cover parameters such as human heat body loss as a function of gender, height, weight, body width, thermal insulation, as well as environmental dimensions and types of construction [1].

Traditionally two main approaches have been considered for human body thermal comfort. The first approach is the classical steady state method developed by Fanger [2-3], based on a heat-balanced model of the human body, operating on the principle mean thermal sensation of a group of people which is described through a predicted mean vote (PMV) and the predicted percentage dissatisfied (PPD). The model considers variables such as clothing, indoor air temperature, indoor mean radian temperature, indoor air velocity, indoor air humidity, and body metabolism. The second approach has been presented by [4]. This approach implements an adaptive model which considers differential changes in an environment's temperature due to people number change that causes this comfort and works to mend the gap and restore human body thermal comfort. Similar results were reported by the authors in [5]. The model is based on the assumption that humans are active entities hence they interact with the surrounding environment.

Thermal comfort can be classified into three classes according to their PMV values under assumed local thermal comfort criterion. These classes either offer users a higher percentage of thermal comfort while 
consuming more energy or compare spaces with greater thermal variation. It has been demonstrated that thermal comfort varies as a function of gender, with women in general more sensitive to cool and less sensitive to humidity than men. Men feel comfortable in a slightly cooler environment, whereas women prefer a warmer environment. Many authors have reported this, among them [6-10].

In a controlled environment, thermal comfort is certainly affected or modulated by the body heat balance which is a function of clothing and metabolic heat rate, with susceptibility to the air rate and humidity, which in turn affects the PMV and PPD coefficients [5, 10, 11]. In this paper, the comfort temperature for males and females are investigated with the presentation of adaptive air conditioning system operating under a mixed-mode strategy (naturally ventilated and/or air-conditioned) and one fully airconditioned strategy. Overall, the comfort temperature was found to be lower for females in comparison to males, which agrees with the published literature, regardless of the ethnic origins of the tested people and/or the country of origin $[7,12,13]$. The adaptive control system presented in this work covers thermal sensation and comfort under stable and transient conditions [14-18]. Such a proposed system can be applied in critical places such as hospitals and chemical plants

Biometric recognition is a recognition technique that employs physical or behavioural characteristics of the human body to identify a person [19]. Biometric recognition techniques utilise the difference in body features for recognition. Image recognition is one of the more common biometric techniques used in many applications [20-24]. This method uses human image data to distinguish one person from another. Currently, a thermal image-based recognition system is proposed as an addition to a visiblelight recognition system. A block diagram of the proposed thermal image profiling system, which enables uniform temperature distribution by the implemented control system, is shown in Figure 1.

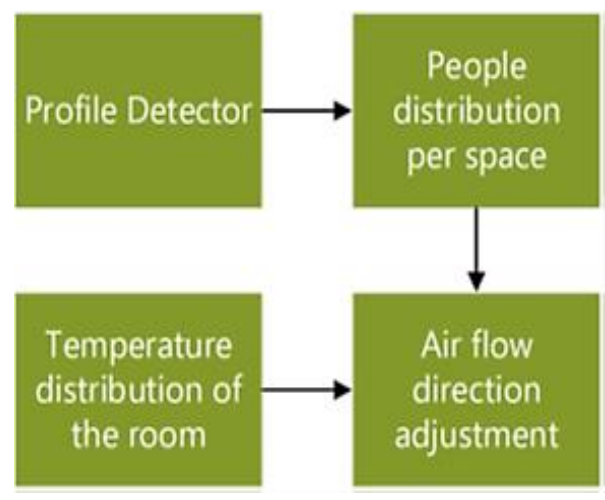

Figure 1. Thermal image system

Temperature gender classification and control (TGCC) using image-based methods is an important subject, as gender is one of the biometric attributes of people, which can play an important role in advanced control systems. Previous research has concentrated on investigating how to infer gender from the facial image of a person with high precision [25, 26]. Recently, excellent work has been carried out in gender classification, specifically when the facial details of a person are not clearly visible. Moreover, under some circumstances facial gender specification might fail.

With the recent advances in wireless sensing and communication technologies, wearable sensors and their recognition have become increasingly important, such sensors enabling continuous sensor monitoring, data collection, and analysis. Radio frequency identification (RFID) technology describes a system transmission mechanism to identity an object or a person wirelessly [27, 28]. The system consists of a tag, a reader, and RFID middleware [29]. Tags are placed on objects or with people, and are generally one of two types; namely 'active' tags (which require a power source) and passive tags (which react by capturing power from an incoming radio frequency) [30]. An RFID reading system acquires data stored in tags and passes that data to a database for additional processing. The middleware works on the RFID data and filters out incomplete or multiple reads from the same tags [31]. After filtering, post processing is carried out, which includes data normalisation, clustering, and cleaning, which results in useful information which can be used by the control system in the correlation and temperature control process. Figure 2 shows a gender-based RFID system, which can be connected to a thermal image profiling system for accurate recognition and uniform temperature distribution. 


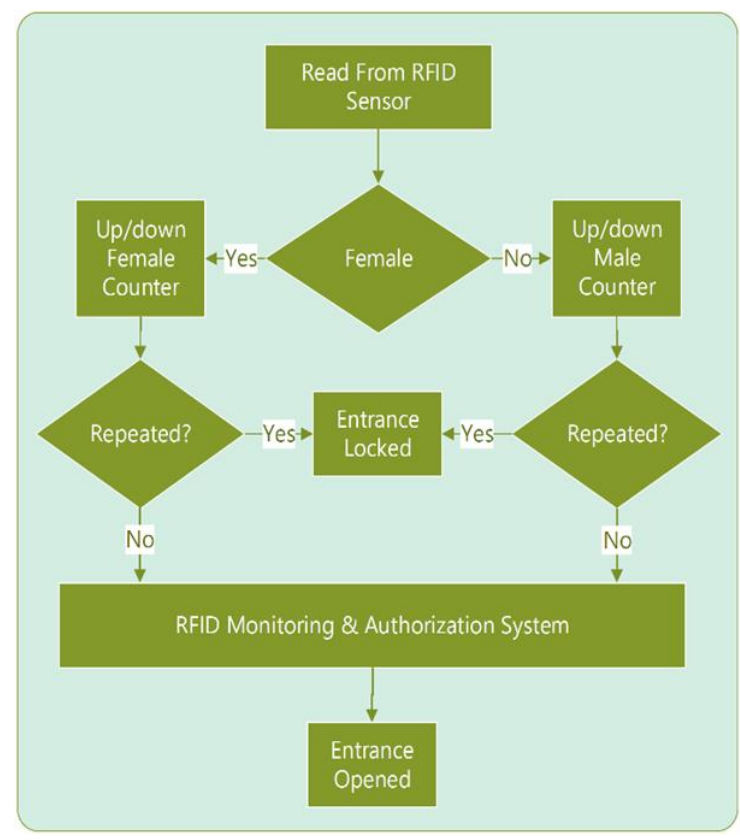

Figure 2. Gender-based RFID system

\section{RESEARCH METHOD}

By studying the behaviour of many kinds of sensors, it has been shown that the most suitable one for the proposed work is the LM35 temperature sensor [32], as shown in Figure 3. This sensor overcomes the non-linear effects that occur with some other sensors, simplifying the sensor input circuitry. Another benefit is that the output voltage is higher than other sensors (such as a thermistor) and therefore an amplifier is not necessary.

The relationship between the output voltage and the measured temperature using an LM35 sensor has been tested in a biomedical instrumentation laboratory at Al-Ahliyya Amman University (AAU), to establish the sensor's sensitivity. Two experiments were conducted; the first referring to the response of the LM35, and the second representing a mean skin temperature for 100 samples-a chosen sample of fifty healthy males and fifty healthy females from the medical engineering department at AAU, with an average age of 20-25 years, an average weight of $76.11 \mathrm{~kg}$ (males) and $57.92 \mathrm{~kg}$ (females), respectively, in the laboratory with an ambient temperature of $25^{\circ} \mathrm{C}$. The skin and core temperature, length, and weight were measured using the following tools:

- $\quad$ Mercury thermometer: to measure the core temperature.

- Scale for weight body: to measure the weight.

- $\quad$ Temperature skin sensor LM35.

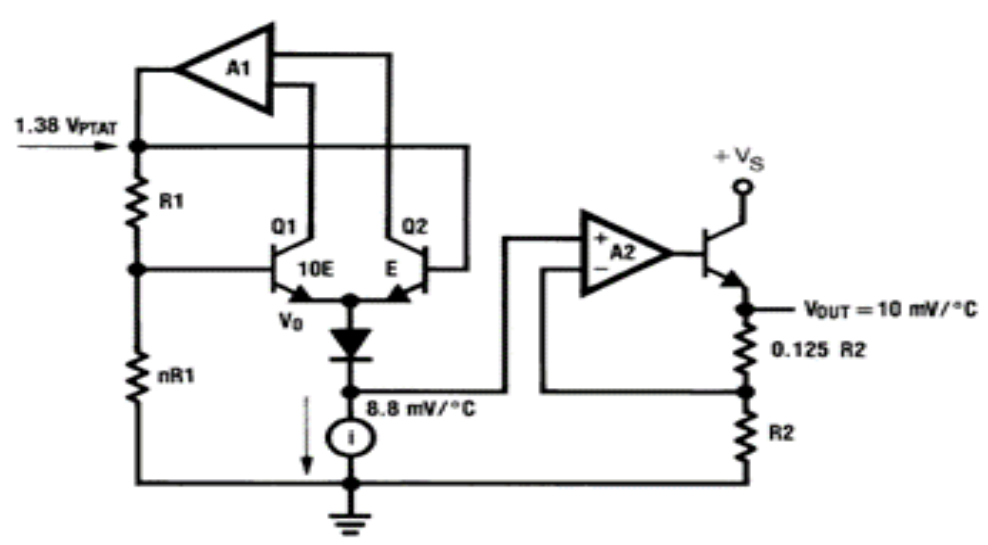

Figure 3. Temperature sensor LM35 


\section{RESULTS AND DISCUSSIONS}

Figure 4 shows the average body temperature for tested males and females as a function of height. Height is taken as a representation of the change in the overall body radiation area as the candidates were selected with an average chest width of $50 \mathrm{~cm}$ [33]. Figure 5 shows the relationship between females and males after elimination of both height and chest variables.

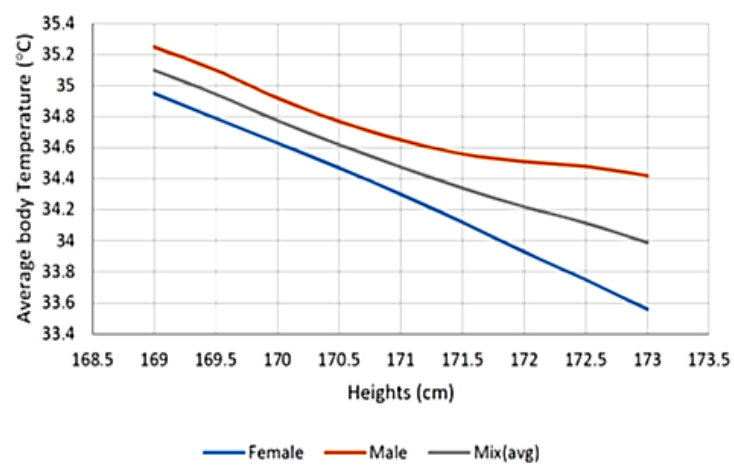

Figure 4. Effect of height with assumed chest width on average body temperature variation

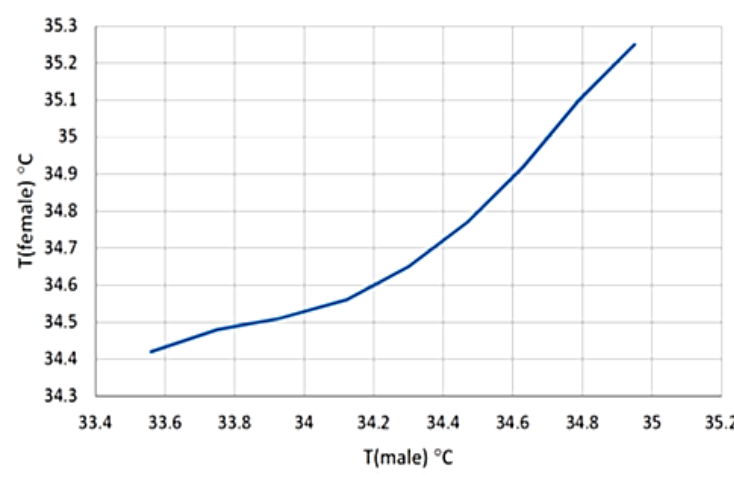

Figure 5. Relationship between females and males body temperature variation

To allow the design of the AG-TCS, Figure 4 was used to enable a clearer understanding of the relationship between females' and males' temperatures as a function of variable height and an average chest width of $50 \mathrm{~cm}$. This figure shows non-intersecting curves, of decreasing average body temperature as a function of height for both females and males, which indicates that the human body temperature variation tends to change in the same direction, but with different values.

Figure 5 shows a clear relationship between a female's body temperature and a male's body temperature of the form described by (1). This function agrees with all medical and statistical data obtained in different research $[34,35]$. Figure 6 shows the overall system designed for an adaptive temperature control system based on gender recognition. The system was designed and simulated based on the data obtained from Figures 4 and 5. This adaptive gender-based thermal control system (AG-TCS) consists of two main parts, the gender-based RFID system and the controller.

The system can control the temperature of a bounded area, such as a room, by capturing and analysing images based on a gender detection process. Consequently, the gender-based RFID system provides a special signal to the controller, to be processed by it. Based on the signal provided by the genderbased RFID system, the controller sends a correction signal to the air conditioning system to increase or decrease the air flow until a desired temperature is reached, that is comfortable for the number of people occupying the room.

Based on the flowchart shown in Figure 6, an advanced PID control system was designed and implemented as shown in Figure 7. The controller consists of three subsystems, namely male, female and mix subsystems. In addition, the system uses a switch that processes the imagery signal, routing it to the desired subsystem within the controller.

The gender-based RFID system identifies the gender of the people entering/exiting a room using a feature extraction system, while the thermal image system is used to provide profiling of the human body temperature by use of a thermal sensor to capture it. A correlator is used to establish the relationship between temperature and gender. A comparison is made between the correlator signal and the temperature set point to establish an error signal.

The system operates under three conditions according to the error signal. Firstly, if only males exist in the room, then the male subsystem with its process transfer function in (1) is applied to control the air conditioning system. Secondly, if only females exist in the room, then the female subsystem with its process transfer function in (2) is applied. Thirdly, if females and males exist at the same time in the room then the mix subsystem with its process transfer function in (3) is applied.

$$
\begin{aligned}
& \text { Male transfer function }=\frac{1}{0.047 s^{2}-16.152 s+1433.4} \\
& \text { Female transfer function }=\frac{1}{0.011 s^{2}-3.271 s+216.4}
\end{aligned}
$$


Mix transfer function $=\frac{1}{0.018 s^{2}-6.436 s+608.5}$

Figures 8 to 16 shows the results obtained from the designed controller shown in Figure 7 by applying different mixed percentages of males versus females. The results proved the relationship between the mix subsystem transfer function with both male and female subsystems.

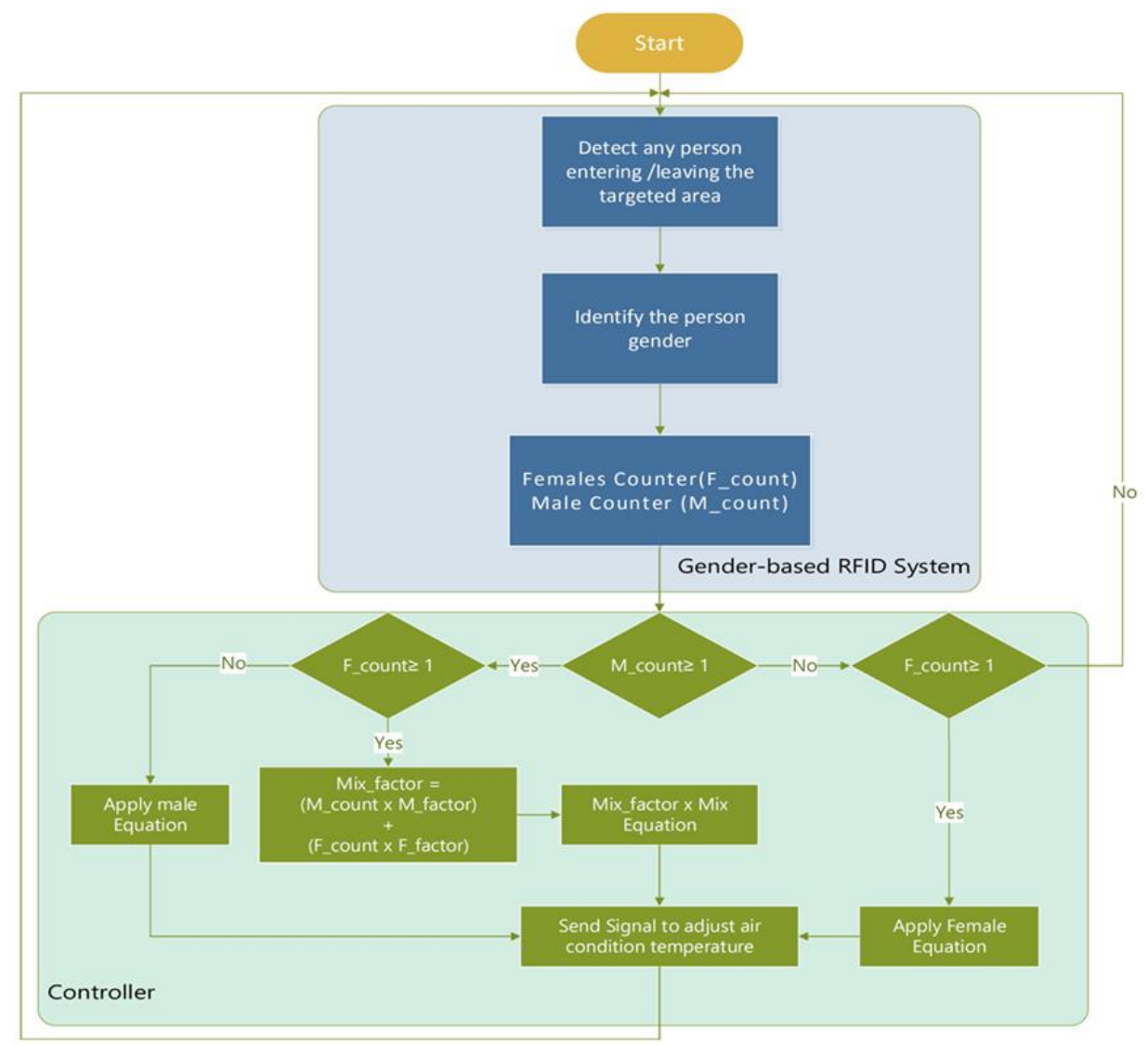

Figure 6. Adaptive gender based thermal control system (AG-TCS) flowchart

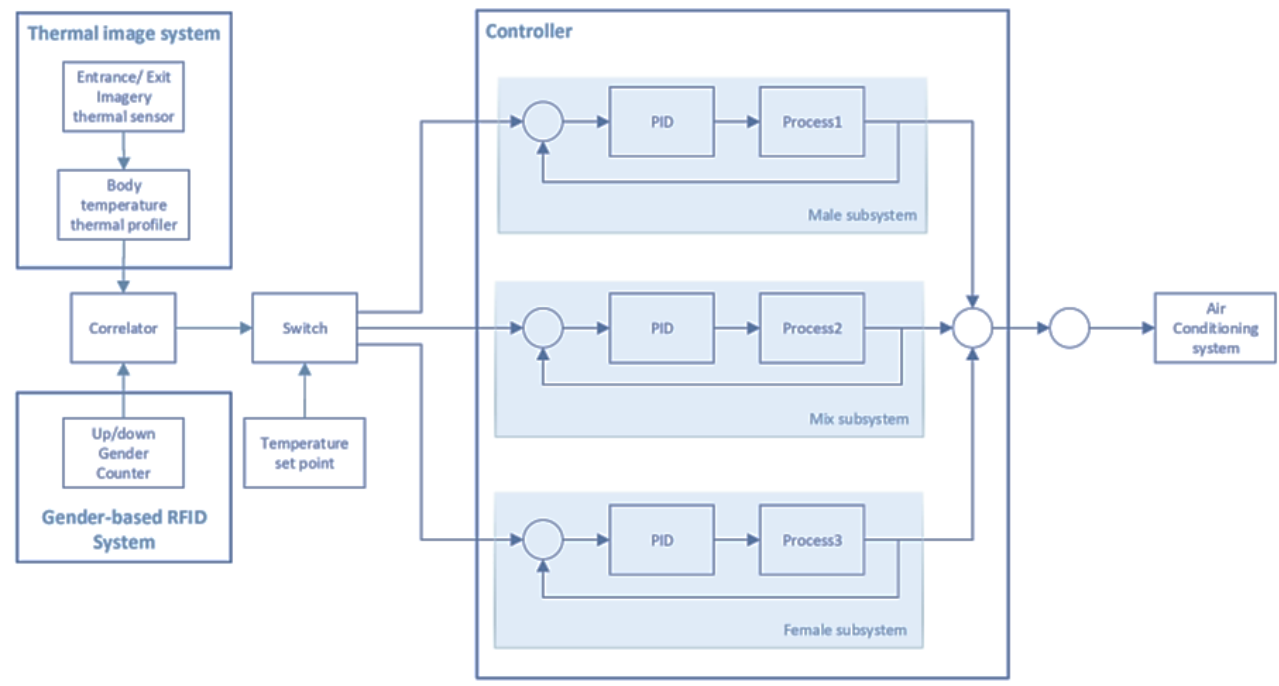

Figure 7. Adaptive gender based thermal control system (AG-TCS) block diagram 


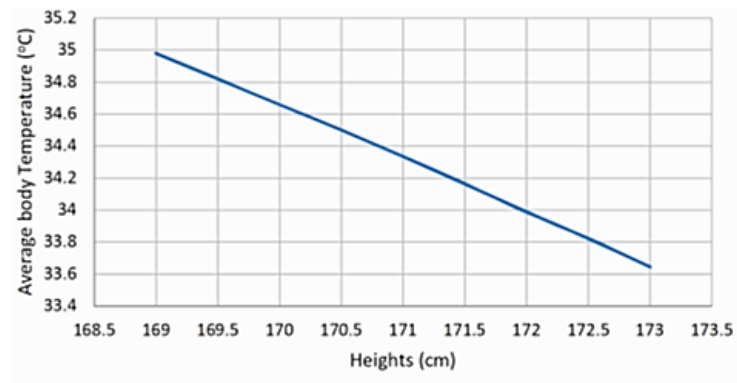

- M10\% \& F $90 \%$

Figure 8. Air conditioning temperature control (males $10 \%$, females $90 \%$ )

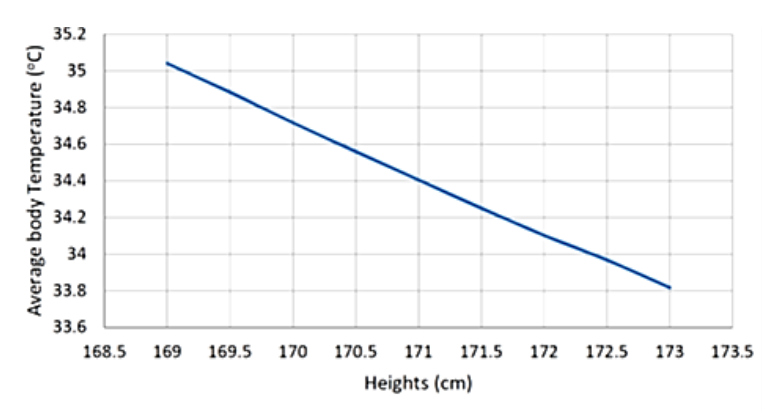

- $\mathrm{M} 30 \%$ \& $\mathrm{F} 70 \%$

Figure 10. Air conditioning temperature control (males 30\%, females 70\%)

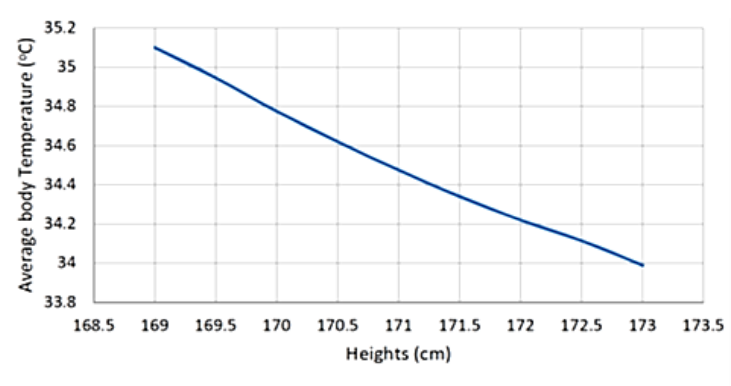

Figure 12. Air conditioning temperature control (males 50\%, females 50\%)

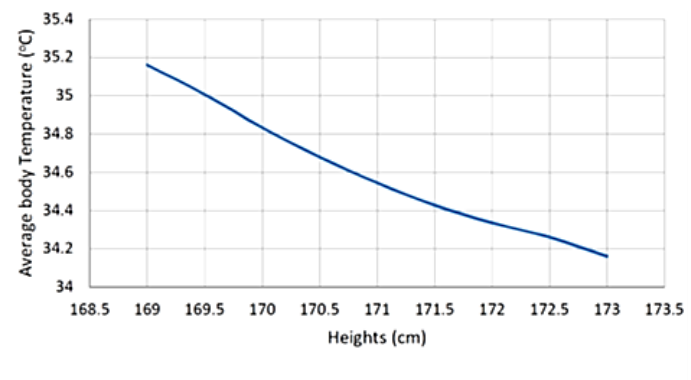

Figure 14. Air conditioning temperature control (males $70 \%$, females $30 \%$ )

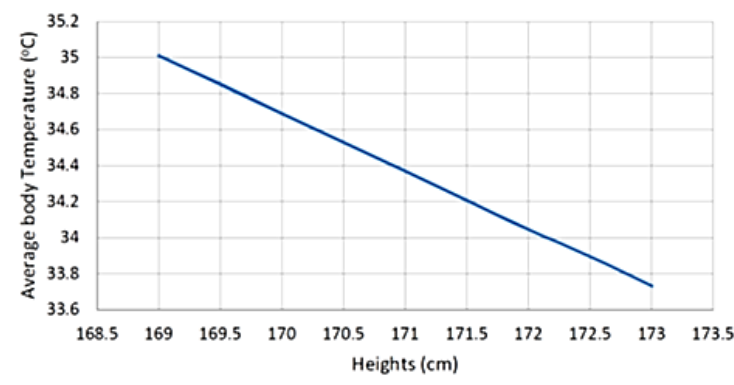

- $\mathrm{M} 20 \%$ \& $\mathrm{F} 80 \%$

Figure 9. Air conditioning temperature control (males $20 \%$, females $80 \%$ )

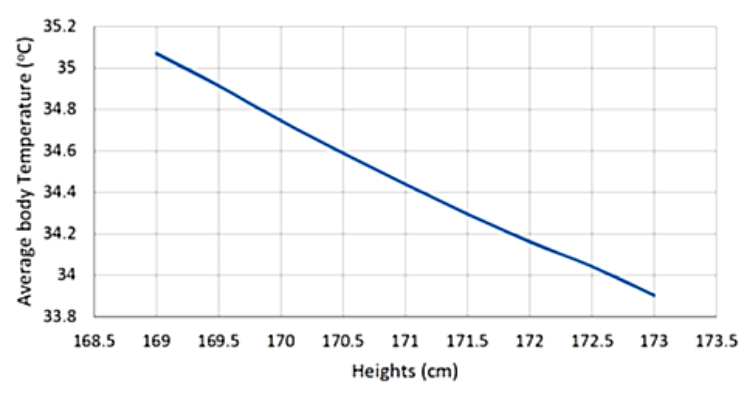

$-\mathrm{M} 40 \% \& \mathrm{~F} 60 \%$

Figure 11. Air conditioning temperature control (males 40\%, females 60\%)

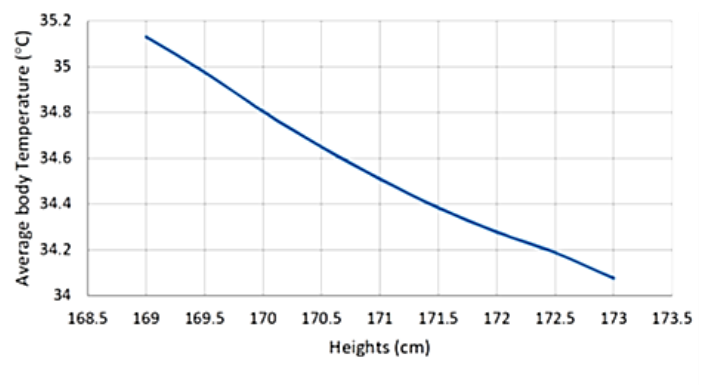

Figure 13. Air conditioning temperature control (males $60 \%$, females $40 \%$ )

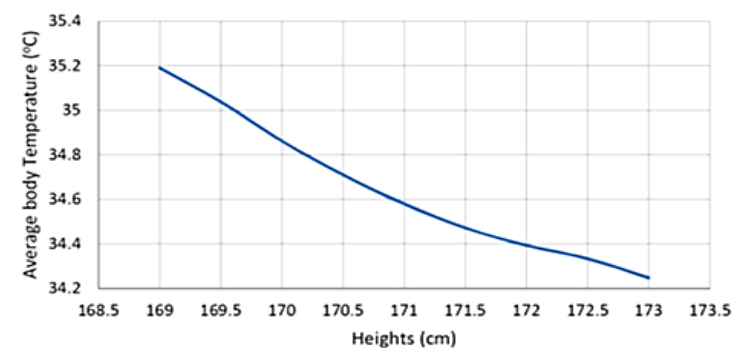

Figure 15. Air conditioning temperature control (males $80 \%$, females $20 \%$ ) 


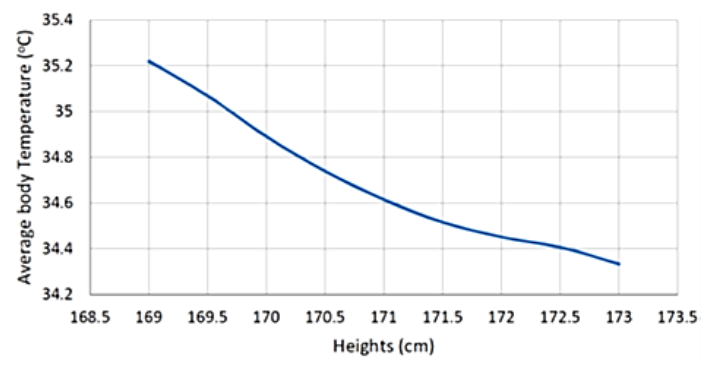

- M90\% \& F $10 \%$

Figure 16. Air conditioning temperature control (males 90\%, females 10\%)

\section{CONCLUSION}

A unique gender temperature relationship was deduced in this work. We managed to prove that each gender could have a specific function describing its characteristics. Each function represents the unique body dynamics in relation to its gender. The new concept of using an RFID and imaging device to recognise gender ratios such that the surrounding temperature could be adjusted was successfully applied. The designed and implemented gender-based air conditioning control system proved to be successful and can be further developed to account for other body parameters and to respond to various environmental dynamics. The presented adaptive system can be transformed into a smart adaptive system using algorithms such as neural networks or statistical pattern recognition techniques.

\section{REFERENCES}

[1] S. Gao, et al., "Numerical investigation on the relationship between human thermal comfort and thermal balance under radiant cooling system," Energy Procedia, vol. 105, pp. 2879-2884, 2017.

[2] R. F. Rupp, N. G. Vásquez and R. Lamberts, "A review of human thermal comfort in the built environment," Energy and Buildings, vol. 105, pp. 178-205, 2015.

[3] F. Schaudienst and F. U. Vogdt, "Fanger's model of thermal comfort: a model suitable just for men?," Energy Procedia, vol. 132, pp. 129-134, 2017.

[4] D. Enescu, "A review of thermal comfort models and indicators for indoor environments," Renewable and Sustainable Energy Reviews, vol. 79, pp. 1353-1379, 2017.

[5] K. Li. R. Katić and W. Zeiler, "Thermophysiological models and their applications: A review," Building and Environment, vol. 106, pp. 286-300, 2016.

[6] J. Li and N. Liu, "The perception, optimization strategies and prospects of outdoor thermal comfort in China: A review," Building and Environment, vol. 170, p. 106614, 2020.

[7] C. Buonocore, et al., "Thermal preference and comfort assessment in air-conditioned and naturally-ventilated university classrooms under hot and humid conditions in Brazil," Energy and Buildings, vol. 211, p. 109783, 2020.

[8] S. Thapa, "Insights into the thermal comfort of different naturally ventilated buildings of Darjeeling, India-Effect of gender, age and BMI," Energy and Buildings, vol. 193, pp. 267-288, 2019.

[9] M. Indraganti, "Gender Differences in Thermal Comfort and Satisfaction in Offices in GCC and Asia," in Gulf Conference on Sustainable Built Environment, 2020, pp. 483-497.

[10] J. K. Maykot, R. F. Rupp and E. Ghisi, "A field study about gender and thermal comfort temperatures in office buildings," Energy and Buildings, vol. 178, pp. 254-264, 2018.

[11] J. Winkler, J. Munk and J. Woods, "Sensitivity of occupant comfort models to humidity and their effect on cooling energy use," Building and Environment, vol. 162, p. 106240, 2019.

[12] M. Indraganti, R. Ooka and H. B. Rijal, "Thermal comfort in offices in India: Behavioral adaptation and the effect of age and gender," Energy and Buildings, vol. 103, pp. 284-295, 2015.

[13] J. Xiong, et al., "Investigation of gender difference in human response to temperature step changes," Physiology \& Behavior, vol. 151, pp. 426-440, 2015.

[14] U. Ciuha and I. B. Mekjavic, "Regional thermal comfort zone in males and females," Physiology \& Behavior, vol. 161, pp. 123-129, 2016.

[15] D. Chong, et al., "Broadening human thermal comfort range based on short-term heat acclimation," Energy, vol. 176, pp. 418-428, 2019.

[16] J. Seifert, L. Schinke and M. Beyer, "Analysis of transient thermal sensation for "overheating" and "subcooling" conditions in a room," International Journal of Ventilation, vol. 19, no. 2, pp. 85-96, 2020.

[17] K. K. L. Lau, Y. Shi and E. Y. Y. Ng, "Dynamic response of pedestrian thermal comfort under outdoor transient conditions," International journal of biometeorology, vol. 63, no. 7, pp. 979-989, 2019.

[18] K. B. Velt and H. A. M. Daanen, "Thermal sensation and thermal comfort in changing environments," Journal of Building Engineering, vol. 10, pp. 42-46, 2017. 
[19] A. K. Jain, A. Ross and S. Prabhakar, "An introduction to biometric recognition," IEEE Transactions on circuits and systems for video technology, vol. 14, no. 1, pp. 4-20, 2004.

[20] Y. Cai, et al., "A fast and robust 3D face recognition approach based on deeply learned face representation," Neurocomputing, vol. 363, pp. 375-397, 2019.

[21] N. Mehendale, "Facial emotion recognition using convolutional neural networks (FERC)," SN Applied Sciences, vol. 2, no. 3, pp. 1-8, 2020.

[22] Y.Kortli, et al., "Face recognition systems: A Survey," Sensors, vol. 20, no. 2, p. 342, 2020.

[23] S. Soltanpour, B. Boufama and Q. J. Wu, "A survey of local feature methods for 3D face recognition," Pattern Recognition, vol. 72, pp. 391-406, 2017.

[24] J. Zhao, J. Han and L. Shao, "Unconstrained face recognition using a set-to-set distance measure on deep learned features," IEEE Transactions on Circuits and Systems for Video Technology, vol. 28, no. 10, pp. 2679-2689, 2017.

[25] M. Afifi and A. Abdelhamed, "AFIF4: Deep gender classification based on AdaBoost-based fusion of isolated facial features and foggy faces," Journal of Visual Communication and Image Representation, vol. 62, pp. 77-86, 2019.

[26] C. B. Ng, Y. H. Tay and B. M. Goi, "Pedestrian gender classification using combined global and local parts-based convolutional neural networks," Pattern Analysis and Applications, vol. 22 no. 4, pp. 1469-1480, 2019.

[27] Y. J. Tu, W. Zhou and S. Piramuthu, "A novel means to address RFID tag/item separation in supply chains," Decision Support Systems, vol. 115, pp. 13-23, 2018.

[28] Y. J. Tu, et al., "Critical Evaluation of RFID Applications in Healthcare," in International Conference on Future Network Systems and Security, vol. 1113, pp. 240-248, 2019.

[29] M. Chuang and W. H. Shaw, "An empirical study of enterprise resource management systems implementation: From ERP to RFID," Business Process Management Journal, vol. 14, no. 5, pp. 675-693, 2008.

[30] A. V. Gotmare, et al., "A Systematic Literature Review on RFID Application in Manufacturing and Supply Chain Management," Industrial Engineering Journal, vol. 12, no. 10, pp. 1-12, 2019.

[31] A. Musa and A. A. A. Dabo, "A review of RFID in supply chain management: 2000-2015," Global Journal of Flexible Systems Management, vol. 17, no. 2, pp. 189-28, 2016.

[32] Texas Instruments, "LM35 Precision Centigrade Temperature Sensors," 2016. [Online]. Available: https://pdf.indiamart.com/impdf/2459592673/MY-1833510/lm35-temperature-sensor.pdf.

[33] Y. L. Choi, et al., "A method for garment pattern generation by flattening 3D body scan data," in International Conference on Digital Human Modeling, vol. 4561, pp. 803-812, 2007.

[34] Z. Wang, et al., "Individual difference in thermal comfort: A literature review," Building and Environment, vol. 138, pp. 181-193, 2018.

[35] P. Li, et al., "A data-driven approach to defining acceptable temperature ranges in buildings," Building and Environment, vol. 153, pp. 302-312, 2019.

\section{BIOGRAPHIES OF AUTHORS}
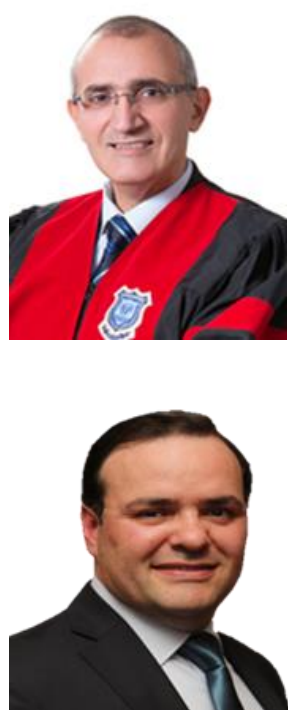

Jamal I. Al Nabulsi received his Diploma degree (Honors) from Leningrad Electro technical Institute, Leningrad, Russia, in 1991, and PhD degree from Saint Petersburg Electro technical University, Saint Petersburg, Russia, in 1999. He joined the teaching staff of the Department of Biomedical Engineering, Faculty of Engineering, The Hashemite University, Zarqa, Jordan from 2002 to 2013. In 2013, he moved to Al-Ahliyya Amman University and he is currently an Associate Professor in Medical Engineering Department there. Dr. Al Nabulsi published 25 scientific papers in journals and in national and international conference proceedings. His research interests include generating and harvesting energy from human motion, investigation of biological media conductance in high frequency electromagnetic field, digitizing ECG signals using digital image processing, and gender related biomedical and control systems.

Bashar E. A. Badr received his B.Sc. degree in Electronics \& Communications Engineering from Al-Ahliyya Amman University, Jordan, in 1999, and his M.Sc. degree in Electrical \& Computer Engineering from the New York Institute of Technology in 2004. He obtained his Ph.D. degree in Microelectronics and Electrical Engineering from Loughborough University, UK in 2014.He was a member of the department's Electronic Systems Design research group. His research focused on Hardware Implementation of Decision Trees for Robotic Applications. $\mathrm{He}$ is currently an Assistant Professor in the Electrical Engineering Department at Al-Ahliyya Amman University, Jordan. His main areas of research interest are control systems, artificial intelligence, machine learning and real-time incremental learning systems. 